\title{
An Alarm at the Gate: Is Anyone Listening? Marijuana Use during Pregnancy from the Lens of a Therapist
}

\author{
Charles R King* \\ Assistant Professor, USA
}

ISSN: 2578-0042

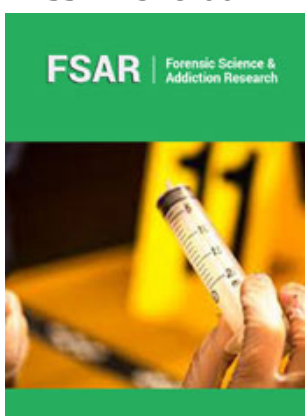

*Corresponding author: Charles $\mathrm{R}$ King, Assistant Professor, USA

Submission: 海June 01, 2019

Published: 毕December 10, 2019

Volume 5 - Issue 2

How to cite this article: Charles R King. An Alarm at the Gate: Is Anyone Listening? Marijuana Use during Pregnancy from the Lens of a Therapist. Forensic Sci Add Res. 5(2). FSAR.000614.2019.

DOI: 10.31031/FSAR.2019.05.000614

Copyright@ Charles R King, This article is distributed under the terms of the Creative Commons Attribution 4.0 International License, which permits unrestricted use and redistribution provided that the original author and source are credited.

\section{Introduction}

The phenomenon of substance abuse during pregnancy has sparked debates and the topic has plagued society for many years. I have been practicing in the area of prenatal and postnatal drug counseling in the state of Louisiana for the past 20 years. There has been a growing concern about the spike in infants born exposed to drugs or alcohol in the past decade. Based on my practice observation, the complexity of this issue has become more detrimental in the last eight years. The accurate identification of prenatal drug exposure is important not only to understand the nature and magnitude of the problem, but also to determine appropriate medical and psychosocial intervention. The prevalence of prenatal drug exposure is very difficult to estimate because of flaws in all methods of identification [1]. According to the Louisiana Department of Children and Family Services report, the number of infants exposed to drugs or alcohol before birth has tripled in Louisiana from 2008 to 2016. It was reported that 569 newborns were delivered in 2008 with drugs or alcohol in their systems at birth and that number jumped to 1,659 in the year of 2016 [2]. The public is aware of the opioid crisis that exists but in my practice most of the cases has been marijuana exposed newborns.

In a closer look at the increased use of substances, I have observed an increase in the use of marijuana during pregnancy. Some women report using marijuana to treat severe nausea associated with their pregnancy. The data on prenatal drug use supports using marijuana during pregnancy exposes not just the mother but also her developing fetus to the substances and can have potentially deleterious and even long-term effects on exposed children [3]. The risk of using marijuana during pregnancy is unrecognized by the general public, but infants and children exposed prenatally to marijuana have a higher incidence of neurobehavioral problems [4]. Marijuana and other compounds in marijuana mimic the human brain's cannabinoid-like chemicals, thus prenatal marijuana exposure may alter the developing endocannabinoid system in the fetal brain, which may result in attention deficit, difficulty with problem solving, and poorer memory [5]. And in light of the growing trend of pregnant women turning to marijuana for morning sickness and other symptoms, the American Academy of Pediatrics issued its first official guidelines on marijuana use, pregnancy and breastfeeding in 2018. In their new recommendations, the group reaffirms that pregnant and nursing moms should not use marijuana in any form because it isn't safe for them or their babies [6,7]. As the hype about marijuana continue to escalate, in recent articles in the Journal of the American Medical Association noted there is very little scientific evidence to support the use of medical marijuana. It is obvious that there is a massive treatment gap because there appears to be a large number of childbearing females that need substance abuse treatment for marijuana use but few receive it [7]. In my practice, I hear daily such statements as, "I did not disclose my drug use and seek treatment because I feared my children will be removed from my home and my parental rights may be altogether terminated." There were some cases where mothers reported that they did mention their use of marijuana to their obstetrician, but nothing happened.

There is certainly an alarm at the gate that needs attending. There should be more effort to reach mothers using drugs before they give birth. There should be more programs in 
place to lure addicted women into prenatal treatment by forsaking criminal penalties for their drug use. I believe drug treatment programs should be available for all drug-abusing pregnant women and parents of infants as well as women of childbearing age, and the programs should be comprehensive and responsive to other related needs of these families, including mental health, health, developmental, parenting education and other support services. Treatment programs should be family-based and include partners as well as other siblings. With the legalization of recreational marijuana in several states and broadening public acceptance regarding marijuana use it is imperative to understand how to optimize counseling for women using marijuana during pregnancy.

\section{Conclusion}

In conclusion, pregnancy can be a wondrous time in life for women and a powerful motivator to pursue healthy behaviors, but I have discovered the state of pregnancy itself is often not enough to end the use or abuse of substances thought to be dangerous to the fetus. There must be a coordinated system of care between the medical community and other health experts to educate women on the harmful effects of substances.

\section{References}

1. Child Welfare Information Gateway (2012) Parental drug use as child abuse. Department of health and human services, Children's Bureau, Washington, DC, USA.

2. Child Welfare League of America (1998) Alcohol and other drug survey of state child welfare agencies. Washington, DC, USA.

3. Westfall RE, Janssen PA, Lucus P, Capler R (2006) Survey of medical cannabis use among childbearing women: patterns of its use in pregnancy and retroactive self-assessment of its efficacy against morning sickness. Complement Ther Clin Pract 12(1): 27-38.

4. Asch RH, Smith CB (1986) Effects of delta 9-THC, the principal psychoactive component of marijuana during pregnancy in rhesus monkey. J Reprod Med 31(12): 1071-1081.

5. Mark K, Desia A, Terplan M (2016) Marijuana use and pregnancy: Prevalence, associated characteristics, and birth outcomes. Arch Womens Ment Health 19(1): 105-111.

6. (1999) National center on addiction and substance abuse no safe haven: Children of substance-abusing parents: The National Center on Addiction and Substance Abuse at Columbia University, New York, USA.

7. Roberson EK, Patrick WK, Hrwitz EL (2014) Marijuana use and maternal experience of severe nausea during pregnancy in Hawaii. Hawaii J Med Public Health 73(9): 283-287. 